\title{
Laparoscopic total extraperitoneal repair under spinal anesthesia versus general anesthesia: a randomized prospective study
}

This article was published in the following Dove Press journal:

Therapeutics and Clinical Risk Management

27 October 2016

Number of times this article has been viewed

\author{
Turgut Donmez' \\ Vuslat Muslu Erdem² \\ Oguzhan Sunamak ${ }^{3}$ \\ Duygu Ayfer Erdem² \\ Huseyin Imam Avaroglu' \\ 'Department of General Surgery, \\ ${ }^{2}$ Department of Anesthesiology and \\ Reanimation, Lutfiye Nuri Burat \\ State Hospital, ${ }^{3}$ Department of \\ General Surgery, Haydarpasa Numune \\ Training and Research Hospital, \\ Istanbul, Turkey
}

Background: Laparoscopic total extraperitoneal (TEP) inguinal hernia repair is a well-known approach to inguinal hernia repair that is usually performed under general anesthesia (GA). To date, no reports compare the efficacy of spinal anesthesia (SA) with that of GA for laparoscopic hernia repairs. The purpose of this study was to compare the surgical outcome of TEP inguinal hernia repair performed when the patient was treated under SA with that performed under GA.

Materials and methods: Between July 2015 and July 2016, 50 patients were prospectively randomized to either the GA TEP group (Group I) or the SA TEP group (Group II). Propofol, fentanyl, rocuronium, sevoflurane, and tracheal intubation were used for GA. Hyperbaric bupivacaine $(15 \mathrm{mg})$ and fentanyl $(10 \mu \mathrm{g})$ were used for SA to achieve a sensorial level of $\mathrm{T}_{3}$. Intraoperative events related to SA, operative and anesthesia times, postoperative complications, and pain scores were recorded. Each patient was asked to evaluate the anesthetic technique by using a direct questionnaire filled in 3 months after the operation.

Results: All the procedures were completed by the allocated method of anesthesia as there were no conversions from SA to GA. Pain was significantly less for $1 \mathrm{~h}(P<0.0001)$ and $4 \mathrm{~h}$ $(P=0.002)$ after the procedure for the SA and GA groups, respectively. There was no difference between the two groups regarding complications, hospital stay, recovery, or surgery time. Generally, patients were more satisfied with SA than GA $(P<0.020)$.

Conclusion: TEP inguinal hernia repair can be safely performed under SA, and SA was associated with less postoperative pain, better recovery, and better patient satisfaction than GA.

Keywords: spinal anesthesia, general anesthesia, TEP, inguinal hernia

\section{Introduction}

Incidence of inguinal hernia has been increasing, with 500,000 new cases every year. ${ }^{1}$ Most surgeons prefer open hernia repair techniques; ${ }^{2}$ however, more recently, both surgeons and patients have begun to prefer minimally invasive techniques, which result in less pain, early work return, less incidence of infection, better cosmetic results, and better patient satisfaction. ${ }^{3-6}$ It is estimated that in the USA $15 \%-20 \%$ of hernia repairs are performed laparoscopically. ${ }^{2}$ Total extraperitoneal (TEP) inguinal hernia repair is the preferred method among the existing laparoscopic techniques. Unlike other techniques, TEP does not require the intraperitoneal cavity to be entered, meaning that intra-abdominal complications such as organ injury and postoperative ileus can be avoided. One disadvantage is its learning curve-dependent difficulty, ${ }^{7}$ and the surgical result depends on the experience of the surgeon. Another disadvantage of TEP inguinal hernia repair is the necessity for general anesthesia (GA). ${ }^{8-10} \mathrm{GA}$ is preferred by the surgeons because it provides complete muscle relaxation in laparoscopic hernia repair. Only few studies
Correspondence: Turgut Donmez Department of General Surgery, Lutfiye Nuri Burat State Hospital, 223.cd.23G Atakent mh. Güneșparkevleri 3. Etap.B2 D36, 34300 Istanbul, Turkey

Tel+905347400967

Emailsurgeont73@hotmail.com 
reported the use of local, epidural, or spinal anesthesia (SA) in TEP inguinal hernia repair. ${ }^{1-15}$ Yet no study is available that compares the use of SA and GA in TEP inguinal hernia repair, a lacuna that the present research addresses.

\section{Materials and methods Study design and patient selection}

This prospective randomized study was conducted at the Department of General Surgery at Lutfiye Nuri Burat State Hospital. Patients who underwent laparoscopic TEP repair for groin hernias between 25 July and 25 July 2016 were randomized to either the GA or the SA groups (Group I and II, respectively). Randomized distribution of the patients was done with a computer by an independent computer programmer using www. randomization.com. The surgeries were performed by two surgeons under either GA or SA, and the randomization was disclosed to the surgeon only at the time of surgery. Both the surgeons had $>5$ years of experience in laparoscopic surgery.

The surgeons and anesthesiologist participating in the study were unaware of which anesthesia technique was used in which patient. The patients were sent to the operation theater randomly. Patients in both PACU (post-anesthesia care unit) and service patient room were followed up by the anesthesiologists who were unaware of the participated groups. Discharge and follow-up of the patients were done by the surgeons who were not in the surgical team. Data collection and classification were performed by hospital data procession unit, and statistical analysis of the data was done by an independent statistics firm.

Patients were included if they had uncomplicated primary inguinal hernia. Exclusion criteria were as follows:

1. Single or multiple previous lower abdominal surgeries

2. Complicated inguinal hernia (irreducible, obstructed, or strangulated)

3. Recurrent hernias

4. Coagulopathies

5. Patients with musculoskeletal system deformity.

The study was approved by the Haseki Training and Research Hospital Ethical Committee (date, no: 22 July 2015, 234). As this is a clinical trial this was registered with the Turkish National Clinical Trial Number and Republic of Turkey Ministry of Health (No 62560444-900/4423). Written informed consent was obtained from the participants.

\section{Preoperative preparation}

A single-dose prophylaxis with a combination of amoxicillin (1,000 mg) and clavulanic acid (200 mg; Augmentin $1.2 \mathrm{~g}$ intravenous flac, GlaxoSmithKline ${ }^{\circledR}$ ) was given intravenously (IV). All the laparoscopic surgeries as well as GA and SA procedures were performed by the same surgical team and anesthesiologist. The anesthesiologist assessed all the patients during a preoperative visit for anxiety, shoulder pain, or abdominal discomfort. The patients who had been admitted to Group II (SA) were also informed that if these side effects could not be resolved with intravenous midazolam or analgesics, or if the patient preferred, the surgery could be performed with GA.

\section{Anesthetic procedure}

\section{General anesthesia}

Premedication was not used in either group. In the preparation room, $10 \mathrm{~mL} / \mathrm{kg}$ of Ringer's lactate solution was infused IV for $30 \mathrm{~min}$. In Group I, 2-2.5 mg/kg of propofol and $1 \mu \mathrm{g} / \mathrm{kg}$ of fentanyl were introduced IV for induction; then, $0.6 \mathrm{mg} / \mathrm{kg}$ of rocuronium was used to achieve muscle relaxation necessary for intubation. After intubation, ventilation was achieved by using an automated anesthesia device (Dräger Primus ${ }^{\circledR}$; Dräger Medical Systems, Inc., Danvers, MA, USA) on volume control ventilation (VCV) mode. In VCV mode, tidal volume was set to $6-8 \mathrm{~mL} / \mathrm{kg}$, and respiration frequency was set to PetCO $232-36 \mathrm{mmHg}$. Anesthesia was maintained with sevoflurane $(1.5 \%-2 \%)$, an oxygen-air mixture $\left(\mathrm{FiO}_{2}=0.4\right)$, and repetitive rocuronium doses $(0.015 \mathrm{mg} / \mathrm{kg})$. At the end of the surgery, neostigmine (2-2.5 mg) and atropine (1 mg) were given IV to antagonize residual neuromuscular block.

\section{Spinal anesthesia}

Each patient underwent SA and conscious sedation. The patients were placed in a sitting position, and Portex (Keene, NH, USA) Model 15545C-21 spinal kits were used. The lower back was scrubbed with povidone iodine solution and draped in a sterile manner. Xylocaine (1\%) was infiltrated subcutaneously, followed by an 18-gauge introducer needle. A 25-gauge Whitacre needle was advanced until cerebrospinal fluid appeared. The patients randomly received either the hyperbaric bupivacaine $(0.5 \%, 15 \mathrm{mg})$ provided in the kit or preservative-free fentanyl $(10 \mu \mathrm{g})$ introduced intrathecally as the primary anesthetic. Then, the patients were placed in a supine position till the completion of the procedure. No additional local anesthetic was used for the port sites or instilled extraperitoneally. Sedation was provided with midazolam $(2 \mathrm{mg})$, fentanyl $(100 \mu \mathrm{g})$, and a propofol infusion ranging from 0 to $100 \mu \mathrm{g} / \mathrm{kg} / \mathrm{min}$. When fentanyl is insufficient, minimum dose of propofol was used to overcome moderate shoulder pain. Then, the patients were placed in a $15^{\circ}$ Trendelenburg position, and sensorial block 
was examined by using the pinprick test at 1 min intervals. The surgery was begun after the sensorial block reached level $\mathrm{T}_{4}$. The surgery can be converted to GA if anesthesia was insufficient or if shoulder pain, abdominal discomfort, or anxiety was unresponsive to medical treatment. Additional support with other drugs, such as ephedrine and fentanyl, was available, if needed.

\section{Surgical procedure}

All the patients underwent surgery in the supine position. A $15 \mathrm{~mm}$ incision was made in the skin below the umbilicus. The anterior rectus fascia was thereby rendered visible, and a horizontal $10 \mathrm{~mm}$ incision was made through it. After the rectus muscle was exposed, the preperitoneal area behind the muscle was dissected bluntly by using a Kelly clamp. The preperitoneal area was insufflated by using a $10 \mathrm{~mm}$ balloon trocar (Covidien, Parkway, MN, USA). Then, the balloon was removed, and carbon dioxide gas was insufflated into the extraperitoneal space at a pressure of $10 \mathrm{mmHg}$. A zerodegree videoscope was inserted through the port, a $5 \mathrm{~mm}$ trocar port was placed $3 \mathrm{~cm}$ above the symphysis pubis, and another $5 \mathrm{~mm}$ trocar was placed between the camera port and the suprapubic port. The inferior epigastric vessels were identified along the lower portion of the rectus muscle and protected. The anterior superior iliac spine was laterally dissected. The preperitoneal space was dissected, and the herniated sac was retracted by using atraumatic forceps. A $10 \times 15 \mathrm{~cm}$ prosthetic graft was inserted through the camera port and placed on the anterior abdominal wall covering the Hesselbach's triangle, the internal inguinal ring. The graft was fixed to the pubic tubercle with an absorbable Tacker ${ }^{\mathrm{TM}}$ fixation device (Covidien) in all the patients. Surgery was performed by the same surgical team in both the groups. Surgery time was measured as the duration between beginning of the skin incision and skin closure.

\section{Patient monitoring and data collection}

All the patients were closely monitored with continuous electrocardiography, noninvasive arterial blood pressure, heart rate (HR), and peripheric oxygen saturation $\left(\mathrm{S}_{\mathrm{p}} \mathrm{O}_{2}\right)$. All these parameters were recorded in both the groups after the patients had entered the operation theater during the preoperative volume replacement for baseline levels. (These parameters were recorded 3 times at $1 \mathrm{~min}$ intervals at rest.) These parameters were also recorded while inducing anesthesia for Group I and after the anesthesia procedure for Group II. The patients were monitored continuously during the surgery and for $24 \mathrm{~h}$ afterward in the patient room. All the demographic features, the American Society of Anesthesiologists (ASA) classification, comorbidities, the hospitalization period, the surgery time (from incision to last suture), and the total time (from anesthesia induction for Group I and from spinal puncture for Group II to recovery room) were recorded. In addition, maximum sensory block level was also recorded for Group II. Patients with intraoperative hypotension (a decrease of $>30 \%$ in baseline mean arterial pressure or systolic arterial pressure $<90 \mathrm{mmHg}$ ), bradycardia (HR $<50$ beats/min), and hypoxemia $\left(\mathrm{SpO}_{2}<90 \%\right)$ were searched for in both the groups. In Group II, any complaints such as nausea/vomiting, right shoulder pain, anxiety, and abdominal discomfort were also recorded. The surgical field pain level was evaluated with visual analog scale (VAS; $0=$ no pain to $10=$ severe pain). First, VAS levels were recorded in the postoperative recovery room in cooperation with the patients 1 (VAS 1) and at 4 (VAS4), 12 (VAS12), and 24 (VAS24) h after the surgery. Undesirable postoperative events, such as headache, nausea/vomiting, right shoulder pain, anxiety, abdominal discomfort, and urinary retention, were recorded in both the groups. All the patients were asked to evaluate their satisfaction of the procedure as good, normal, or bad. An independent anesthesiologist working in intensive care unit who was unaware of the groups and not included in the study recorded all the data.

Any intraoperative complications such as vascular or nerve injury, peritoneal laceration, and visceral injuries were recorded. Any conversions from TEP to transabdominal preperitoneal (TAPP) or from laparoscopic to open repair were recorded, along with the specific reason for conversion. Bleeding was recorded as mild if no suction irrigation was required, moderate if suction was required at the end of the procedure or to improve vision, and severe if a blood transfusion was required. Other complications, including hematoma or seroma formation and wound infections, were also recorded.

\section{Treatment of adverse events}

The first attempt to treat hypotension was made with $250 \mathrm{~mL}$ saline infusion for $5 \mathrm{~min}$. If it could not be managed with fluid replacement or if systolic pressure was $<90 \mathrm{mmHg}, 5 \mathrm{mg}$ of ephedrine HCI was administered IV. For bradycardia treatment, $0.5 \mathrm{mg}$ of atropine was administered IV. In Group II, $0.015-0.030 \mathrm{mg} / \mathrm{kg}$ of midazolam was given for anxiety and $1-2 \mu \mathrm{g} / \mathrm{kg}$ of fentanyl for shoulder pain and abdominal discomfort. All the patients were infused with 1 L Ringer's lactate and $1 \mathrm{~L}$ isotonic saline within $24 \mathrm{~h}$ after the surgery for fluid replacement. If postoperative VAS was $\geq 4,50 \mathrm{mg}$ 
of tramadol in a $100 \mathrm{~mL}$ saline infusion was introduced IV for $30 \mathrm{~min}$.

\section{Statistical analysis}

Statistical analysis was done by an independent firm on statistics (ARAT Statistics Co.). The results were analyzed by using Statistical Package for Social Sciences for Windows, Version 15.0. Along with descriptive statistical methods (mean and standard deviation), numbers and percentages were also used to compare the quantitative categorical variables, mean, standard deviation, minimum, and maximum for numerical variables.

When a normal distribution of the numerical variables was provided, both the groups were compared by using the Student's $t$-test, and otherwise, they were compared by using the Mann-Whitney $U$-test. The Friedman test was used to compare $>2$ groups as the difference between the variables of dependent-group comparison did not provide a similar situation to normal distribution. Subgroup analyses were carried out by using the Wilcoxon test and interpreted using the Bonferroni correction. $P<0.05$ was considered for statistical $\alpha$ significance.

\section{Results}

Figure 1 shows the patient flow diagram during the study period. In total, 62 patients underwent TEP inguinal hernia repair, of whom 10 were excluded ( 4 were aged $<18$ years, 1 was scheduled for TEP inguinal hernia repair on both sides, and 5 declined to participate). Two patients in Group II were excluded because of spinal block failure and so the surgery was converted to GA. Finally, 25 patients from each group were included in the final analysis.

Patient demographics (eg, gender, age, body mass index, and ASA score) of both the groups were not significantly different (Table 1). The mean age of the patients in Group I was $35.36 \pm 11.40$ years (range $=23-59$ years) and in Group II was $37.16 \pm 10.85$ (range $=23-56$ years). There was no statistically significant difference between these two groups in terms of age or gender distribution $(P=0.570)$.

Fifty patients had a total of 61 hernias, of which 22 were direct and 39 indirect. The majority of the hernias were rightsided $(38,62.3 \%)$. There were $13(40.625 \%)$ direct hernias in Group I and $9(31 \%)$ in Group II $(P=0.542)$. There were $19(59.375 \%)$ indirect hernias in Group I and $20(69 \%)$ in Group II $(P=0.542)$.

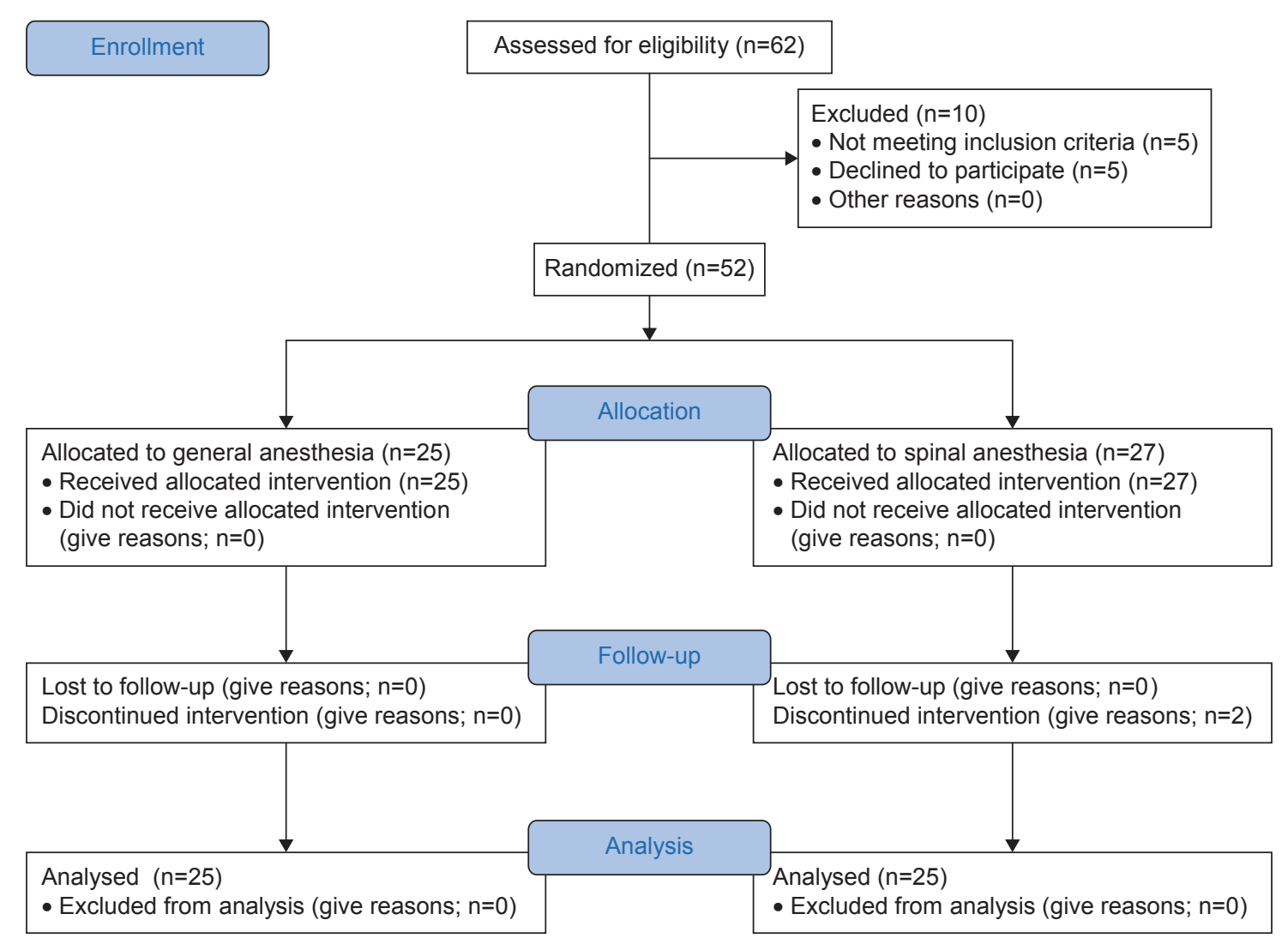

Figure I CONSORT flow diagram.

Notes: Group I, TEP inguinal hernia repair under general anesthesia; Group II, TEP inguinal hernia repair under spinal anesthesia.

Abbreviation: TEP, total extraperitoneal. 
Table I Demographic and surgery-related parameters

\begin{tabular}{|c|c|c|c|}
\hline & $\begin{array}{l}\text { Laparoscopic TEP } \\
\text { general anesthesia }\end{array}$ & $\begin{array}{l}\text { TEP spinal } \\
\text { anesthesia }\end{array}$ & $P$-values \\
\hline Age (years); mean $\pm \mathrm{SD}$ (median) & $35.36 \pm I I .40(37)$ & $37.16 \pm 10.85(36)$ & 0.570 \\
\hline Gender; n (\%) & & & 1.000 \\
\hline Female & $2(8.0)$ & I (4.0) & \\
\hline Male & $23(92.0)$ & $24(96.0)$ & \\
\hline BMI $\left(\mathrm{kg} / \mathrm{m}^{2}\right) ;$ mean $\pm \mathrm{SD}$ (median) & $23.52 \pm 3.45(22.7)$ & $23.96 \pm 3.97(23.2)$ & 0.677 \\
\hline Total duration (min); mean \pm SD (median) & $52.6 \pm 8.82(53)$ & $59.12 \pm 7.95$ & 0.008 \\
\hline Surgery duration (min); mean \pm SD (median) & $36.16 \pm 8.21(35)$ & $40.16 \pm 6.54(39)$ & 0.063 \\
\hline Spinal time $(\min ) ;$ mean \pm SD (median) & & $16.84 \pm 3.82(16)$ & - \\
\hline Drain placement; $\mathrm{n}(\%)$ & $2(8.0)$ & I (4.0) & 1.000 \\
\hline $\mathrm{ASA}^{\mathrm{a}} ; \mathrm{n}(\%)$ & & & 1.000 \\
\hline 1 & $23(92.0)$ & $22(88.0)$ & \\
\hline 2 & $2(8.0)$ & $3(12.0)$ & \\
\hline Discharge time (h); mean \pm SD (median) & $28.16 \pm 4.30(27)$ & $26.8 \pm 2.93(27)$ & 0.396 \\
\hline Karnofsky Performance Scale; mean \pm SD (median) & $98.40 \pm 3.74(100)$ & $98.8 \pm 3.32(100)$ & 0.687 \\
\hline Analgesics need $(h)$; mean \pm SD (median) & $1.12 \pm 0.33(I)$ & $5.2 \pm 0.87(5)$ & $<0.001$ \\
\hline Patient satisfaction; mean \pm SD (median) & $3.96 \pm 0.73(4)$ & $4.44 \pm 0.65(5)$ & 0.020 \\
\hline
\end{tabular}

Notes: aASA score is a global score that assesses the physical status of patients before surgery. Bold indicates significance.

Abbreviations: ASA, American Society of Anesthesiologists; BMI, body mass index; SD, standard deviation; TEP, total extraperitoneal.

The dissection of the extraperitoneal space was graded as easy in $98 \%$ of the patients; it was graded as easy in all the patients from Group II and as difficult in 1 patient from Group I because of a large indirect hernia sac. Space was adequately created in all the patients, and it was achieved by using telescopic dissection.

Anatomical delineation of the inguinal area was satisfactory in $98 \%$ of the patients and was unsatisfactory in only 1 patient in Group I $(P=0.896)$ due to excessive preperitoneal fat (Table 2). There was no injury to the inferior epigastric vessels, vas deferens, other cord structures, or bladder and no major vascular or bowel injury during dissection or insertion of ports in either group. Bleeding was graded as minimal in all the patients in both the groups.

There was no difference in mean surgery time between the two groups $(P=0.063)$. In Group I (GA), the surgery time was $36.16 \pm 8.21 \mathrm{~min}$ (range $=24-52 \mathrm{~min}$ ), and in Group II (SA), it was $40.16 \pm 6.54 \mathrm{~min}$ (range $=30-54 \mathrm{~min}$ ). In Group I (GA), the total surgery time was $52.6 \pm 8.82 \mathrm{~min}$ (range $=39-71 \mathrm{~min}$ ), and in Group II (SA), it was 59.12 $\pm 7.95 \mathrm{~min}$ (range $=50-69 \mathrm{~min}$ ), which was significant $(P=0.008)$. None of the surgeries were converted into an open one.
The mean postoperative hospital stay period was $24.8 \pm 4 \mathrm{~h}$. In Group I, the postoperative stay was $28.16 \pm$ $4.30 \mathrm{~h}$ (range $=22-38 \mathrm{~h}$ ), and in Group II, it was $26.8 \pm 2.93 \mathrm{~h}$ (range $=21-34 \mathrm{~h}$ ). In Group II, 1 patient was kept for $36 \mathrm{~h}$ due to severe pain during the postoperative period. However, there was no statistically significant difference in the hospital stay between the two groups $(P=0.396)$.

The incidence of scrotal edema was significantly higher in Group II $(P=0.529) ; 14 \%$ of the patients developed scrotal edema early in the postoperative period: $3(12 \%)$ in Group I and $4(16 \%)$ in Group II. Using the Mann-Whitney $U$-test, it was found that there was no correlation between scrotal edema development and age, operation time, or the type of hernia $(P<0.05$; Table 3$)$. None of the patients in either group developed either scrotal hematoma or testicular pain. Any recurrence of hernias were not noticed during the immediate postoperative period in either group (Table 3).

The follow-up schedule was 7 days and then 1,3,6, and 11 months (Table 3). The follow-up period ranged from 8 to 11 months (average $=9.6$ months). Pain, seroma formation, infection of wound or graft, and any recurrence of the hernia were recorded during the follow-up.

Table 2 Intraoperative problems in surgical technique

\begin{tabular}{lllll}
\hline & Total $(\mathbf{n}=\mathbf{5 0})$ & GA Group I $(\mathbf{n}=\mathbf{2 5})$ & SA Group II $(\mathbf{n}=\mathbf{2 5})$ & P-values \\
\hline Dissection of extraperitoneal space: easy & $49(98 \%)$ & $24(96 \%)$ & $25(100 \%)$ & 0.896 \\
Anatomical delineation: satisfactory & $49(98 \%)$ & $24(96 \%)$ & $25(100 \%)$ & 0.896 \\
\hline
\end{tabular}

Abbreviations: GA, general anesthesia; SA, spinal anesthesia. 
Table 3 Postoperative complications

\begin{tabular}{|c|c|c|c|c|}
\hline & Total $(n=50)$ & GA Group I (n=25) & SA Group II $(n=25)$ & $P$-values \\
\hline Scrotal edema & $7(14 \%)$ & $3(12 \%)$ & $4(16 \%)$ & 0.529 \\
\hline Seroma within 7 days & $6(12 \%)$ & $3(12 \%)$ & $3(12 \%)$ & 1.000 \\
\hline Seroma within 30 days & $2(4 \%)$ & I (4\%) & I (4\%) & 1.000 \\
\hline Wound infection within 7 days & $3(6 \%)$ & $2(8 \%)$ & I (4\%) & 1.000 \\
\hline Wound infection within 30 days & 0 & 0 & 0 & \\
\hline Recurrence (hernia) at $8-1$ I months (average $=9.6$ ) & 0 & 0 & 0 & \\
\hline
\end{tabular}

Abbreviations: GA, general anesthesia; SA, spinal anesthesia.

Seroma was the most common problem noticed during the 7-day follow-up examination. There was a significant difference in the development of seroma between the two groups $(P=1.000)$. Three (12\%) patients developed seroma in Group I and 3 patients (12\%) in Group II; of these, 1 patient (16.6\%) required aspiration of the seroma during the follow-up. Three patients (6\%) developed superficial wound infection at the umbilical port site. Two (8\%) patients from Group I and $1(2 \%)$ patient from Group II presented superficial surgical site infection of the umbilical port. There was no statistically significant difference between the two groups $(P=1.000)$.

Seroma resolved with the expected management in most patients. Two patients had persistent seroma at the 1-month stage ( $4 \%$ of the patients in both Groups I and II $[P=1.000]$ ). There was no wound or mesh infection or recurrence of hernia at the 1-month follow-up stage. There was no seroma, wound or mesh infection, or recurrence of hernia recorded during any of the 1-, 3-, 6-, 9-, or 11-month follow-up examinations (Table 3 ).

There were higher pain scores after the first hour in Group I than in Group II. Pain score at $1 \mathrm{~h}$ in Group I was $4.80 \pm 0.76$ and in Group II $0.16 \pm 0.37$ (Table 4). The difference between these two groups was statistically highly significant $(P=0.001)$. There was a significant difference in VAS pain scores between these groups after $4 \mathrm{~h}$ : the mean pain score was $2.32 \pm 0.56$ in Group I and $1.72 \pm 0.68$ in Group II $(P=0.002)$. Patients in Group I had higher VAS pain scores $(1.48 \pm 0.59$ and $0.84 \pm 0.55)$ and $(1.28 \pm 0.46$ and $0.76 \pm 0.44)$ than those

Table 4 Postoperative pain scoring (VAS)

\begin{tabular}{llll}
\hline & $\begin{array}{l}\text { Laparoscopic TEP } \\
\text { general anesthesia }\end{array}$ & $\begin{array}{l}\text { TEP spinal } \\
\text { anesthesia }\end{array}$ & P-values \\
\hline Post I VAS & $4.80 \pm 0.76(5)$ & $0.16 \pm 0.37(0)$ & $<\mathbf{0 . 0 0 I}$ \\
Post 4 VAS & $2.32 \pm 0.56(2)$ & $1.72 \pm 0.68(2)$ & $\mathbf{0 . 0 0 2}$ \\
Post I2 VAS & $1.48 \pm 0.59(\mathrm{I})$ & $\mathrm{I} .28 \pm 0.46(1)$ & 0.214 \\
Post 24 VAS & $0.84 \pm 0.55(\mathrm{I})$ & $0.76 \pm 0.44(\mathrm{I})$ & 0.638 \\
\hline
\end{tabular}

Notes: Data presented as mean \pm SD (median). Bold indicates significance. Abbreviations: SD, standard deviation; TEP, total extraperitoneal; VAS, visual analogue scale. in Group II ( $1.28 \pm 0.46$ vs $0.76 \pm 0.44)$ at $12 \mathrm{~h}$ and $24 \mathrm{~h}$ after surgery. However, the difference between the two groups was not statistically significant ( $P=0.214$ vs $P=638$; Table 4).

Hypotension was found in $3(12 \%)$ patients in Group I and $4(16 \%)$ in Group II, not a statistically significant difference $(P=0.529)$. Postoperative nausea vomiting (PONV) was found in $4(16 \%)$ patients in Group I and $1(4 \%)$ in Group II - again not a statistically significant difference $(P=0.349)$. Urinary retention (2 [8\%]) and headaches (2 [8\%]) were found in patients in Group II and in no one in Group I, which was again not statistically significant $(P=0.490)$. Shoulder pain was found in $3(12 \%)$ patients in Group I and $4(16 \%)$ in Group II, which was not statistically significant $(P=0.529$; Table 5$)$.

Patient satisfaction was recorded at the end of 3 months on a Likert scale and Karnofsky Performance Scale. Majority of the patients in Group II were highly satisfied with the procedure in terms of recovery, pain, and return to normal activity (Likert scale; $P=0.02$ ). But, according to the Karnofsky Performance Scale, Group I had 98.40土3.7 and Group II had 98.8 \pm 3.32 , which is not statistically significant $(P=0.687$; Table 1).

\section{Discussion}

The feasibility of SA as a choice for anesthesia in a TEP laparoscopic hernia repair is discussed. This technique has been used in the clinics for 3 years. Inguinal hernia repair is one of the most frequently performed operations in general surgery.

Table 5 Adverse effects

\begin{tabular}{lllllll}
\hline & \multicolumn{2}{l}{$\begin{array}{l}\text { TEP general } \\
\text { anesthesia }\end{array}$} & & \multicolumn{2}{l}{$\begin{array}{l}\text { TEP spinal } \\
\text { anesthesia }\end{array}$} & P-values \\
\cline { 2 - 3 } & $\mathbf{n}$ & $\%$ & & $\mathbf{n}$ & $\%$ & \\
\hline Hypotension & 3 & 12.0 & & 4 & 16.0 & 0.529 \\
Vomiting & 4 & 16.0 & & 4 & 4.0 & 0.349 \\
Shoulder pain & 3 & 12.0 & & 4 & 16.0 & 0.529 \\
Urinary retention & 0 & 0 & & 2 & 8.0 & 0.490 \\
Headache & 0 & 0 & & 2 & 8.0 & 0.490 \\
\hline
\end{tabular}

Abbreviation: TEP, total extraperitoneal. 
The reported advantages of laparoscopic repair are as follows: less pain in the early postoperative period, fewer analgesics being necessary, better cosmetic results, and the ability to return to work earlier. ${ }^{8}$ Forty randomized clinical studies were analyzed by the National Institute of Clinical Excellence 2001, and laparoscopic hernia repair was found to be better than open repair because it resulted in less pain and faster healing. ${ }^{16}$ Laparoscopic repair is performed by using two methods: TEP and TAPP. TEP is believed to be superior because it avoids intraperitoneal access and related complications. ${ }^{17}$ Nevertheless, it still suffers from the important disadvantage that it requires GA. ${ }^{8-10}$

GA has been preferred for laparoscopic hernia repairs for various reasons; some of them are as follows:

1. Patients request complete analgesia.

2. GA is easier to "learn" and "teach."

3. The learning curve for performing TEP under GA is faster.

4. Patients prefer "complete unconsciousness" so they do not know what is going on.

5. Patients' fear "needle stick at waist."13

Ease of dissection, forming operation field and dissection of it, as well as the delineation of anatomical landmarks for the two techniques was compared. The surgeon graded the difficulty just after completing the surgery. There was no difference in any of the aforementioned parameters for the two methods of dissection, as graded by the surgeons. There is no published study that compares these parameters between the two groups. However, Sung et al compared the drugs used in SA in TEP, reporting that SA provided a good muscle relaxation and operative field in both the groups. ${ }^{18}$

No data are available in the literature comparing the surgery times for the two groups. The surgery duration for TEP carried out under GA and SA was compared, finding that SA had a longer mean surgery duration (36.16 min for Group I vs 40.16 min for Group II); however, the difference was not statistically significant $(P=0.063)$. On the other hand, the total surgery time was longer in Group I (52.60 min for Group I vs $59.12 \mathrm{~min}$ for Group II) and statistically significant $(P=0.008)$. It was hypothesized that this difference was a result of the SA procedure taking longer time.

Incidence of intestinal injury in laparoscopic hernia repair was reported to be between $0 \%$ and $0.06 \%{ }^{19,20}$ Most injuries were suffered during the entry phase, and the small bowel was most likely to be injured. It can be repaired peroperatively by an experienced surgeon. ${ }^{21}$ Lau et al reported no visceral organ injury in their series of 82 surgeries. ${ }^{22}$ No visceral organ injury was experienced in the present study in either group.
Comparison studies and large case series have shown that the rate of technique-independent serious adverse effects was very low and that TAPP was slightly advantageous compared to TEP $(0.25 \%$ vs $0.42 \%)$ in terms of vascular injury. ${ }^{23}$ No vascular injury was found in either of the TEP groups.

Scrotal edema is a common complication of laparoscopic hernia repair. ${ }^{21}$ Age, giant hernia defect, scrotal hernia sac presence, and remnant distal hernia sac were among the factors contributing to edema development. ${ }^{24}$ Misra et al reported that the incidence of scrotal edema is $17.8 \%$ in their randomized prospective clinical study. ${ }^{25}$ Another study comparing TAPP and TEP methods reported its incidence as $9.4 \%$, which was less in the TEP group. ${ }^{26}$ In the present study, in total, scrotal edema was observed in 7 patients: 3 $(12 \%)$ in Group I and $4(16.5 \%)$ in Group 2; there was no significant difference between the groups $(P=0.529)$.

Seroma, along with scrotal edema, is a common postoperative complication occurring following laparoscopic hernia repair. ${ }^{21}$ As it simulates recurrence during the postoperative period, it is a source of anxiety for both surgeon and patient. Incidence of seroma has not been observed to increase in single-port methods. Seroma incidence in TEP repairs leading to recurrence is low in experienced centers. Seroma incidence following TEP repairs was reported to lie between $1.13 \%$ and $37.9 \% .^{26-31}$ Lau et al reported the factors likely to increase the risk of seroma to be age, giant scrotal hernia, distal remnant hernia sac, and hernia sac descending into the scrotum. ${ }^{24}$ They also pointed to excess cord dissection, the risk of the remnant hernia sac bleeding, and an extended operation duration to be among the causes. The same factors were responsible for the seroma that occurred in the present cases. The incidence of seroma in the present series was $12 \%$ (6 patients) after the first postoperative week, but it was only $4.0 \%$ at the end of the first month. There was no significant difference between the two groups. No additional procedure, such as aspiration, was necessary, and seroma vanished spontaneously on follow-up.

Urinary retention is also a side effect of laparoscopic hernia repair. Its incidence in TEP repairs under GA is between $4.2 \%$ and $12.0 \% \%^{27,28,30}$ and under SA between $3.33 \%$ and $18.05 \% .{ }^{13,18}$ Ismail et al compared mesh-fixed and non mesh fixed patients in their retrospective clinical study, and the nonfixed group under GA had no urinary retention. The mesh-fixed SA group showed significantly higher urinary retention rate than the nonfixed group (3\% vs 30\%; $P<0.0001) .{ }^{32}$ In the present study, the retention rate was $8 \%$ ( 2 patients) in Group II and $0 \%$ in Group I. Mesh was fixed in 
both the groups, and there was no statistically significant difference $(P=0.490)$. Urinary catheterization was not required in either of the two groups.

Hypotension may be found during GA and SA. Sung et al reported that the use of intrathecal fentanyl during TEP repair under SA decreased the incidence of hypotension. ${ }^{18}$ Sinha et al reported a hypotension rate of $15.63 \% .{ }^{15}$ The hypotension rate was higher in the SA group than in the GA group in the present study (4 patients [16\%] vs 3 patients [12\%]), but there was no significant difference $(P=0.529)$.

Headache after dural puncture is a common side effect of spinal and epidural anesthesia, and its incidence is between $0.5 \%$ and $24 \% .^{33}$ Distension of intracranial vessels and an increase in brain blood flow can play a primary role in postdural pain headache formation. ${ }^{34}$ The headache rate in TEP repair under SA was reported to be between $0 \%$ and $9.7 \% .^{13,15,18}$ Only 2 patients ( $8 \%$ ) in the SA group experienced headaches in the present study. Again, there was no statistically significant difference between the groups $(P=0.490)$. Headache was treated with intravenous fluid replacement and $50 \mathrm{mg}$ tramadol.

PONV (post operative nausea and vomiting) is an important postoperative adverse effect that decreases patient satisfaction. ${ }^{35}$ Intravenous opioid use during operation and the postoperative period was blamed for increasing the risk of PONV. ${ }^{36,37}$ Sung et al reported that the rate of PONV was higher for patients who had been administered with intrathecal fentanyl during TEP repair under SA than for a control group (22.2\% vs $16.7 \%) .{ }^{18}$ PONV was higher in the GA group than in the SA group (4 patients [16\%] vs 1 patient [4\%]), but it was not statistically significant $(P=0.349)$.

Shoulder pain was one of the most important causes for converting from SA to GA during TEP repair. It is caused by irritation of the diaphragm and peritoneum by the $\mathrm{CO}_{2}$ used in the pneumoperitoneum and is carried by phrenic and cervical nerves. ${ }^{18}$ The development of shoulder pain during TEP under SA is considered important because it indicates tearing of the hernia sac during dissection, thereby passing $\mathrm{CO}_{2}$ into abdomen and increasing intra-abdominal pressure. Shoulder pain incidence was reported in 10\%-64\% of cases. ${ }^{38,39}$ Sung et al reported that intrathecal fentanyl use decreased the pain incidence significantly compared to a control group (9 patients [25\%] vs 18 [50\%]). They also reported that $21(84 \%)$ out of 25 patients who developed pneumoperitoneum due to tearing of the hernia sac experienced shoulder pain, and $6(12.76 \%)$ out of 47 patients who developed no pneumoperitoneum also experienced shoulder pain. ${ }^{18}$ In the present study, postoperative shoulder pain occurred a little more often in the SA than in the GA group (4 patients [16\%] vs 3 patients [12\%]), but it was statistically insignificant $(P=0.529)$. Pneumoperitoneum due to a torn hernia sac developed in 3 patients in the GA group and 3 patients in the SA group in the present study. The etiology of the shoulder pain was the same as reported in other studies. Peroperative shoulder pain was managed by administering $50 \mathrm{mg}$ fentanyl IV. None of the patients in the present study required conversion to GA. Postoperative shoulder pain was relieved by administering $50 \mathrm{mg}$ tramadol IV.

Pain is the most common complaint following hernia repairs. ${ }^{21}$ No studies comparing GA and SA in TEP repair were available, obviously none comparing the level of pain for the two procedures. Krishna et al identified age, gender, mesh fixation, seroma development, and operation duration as the independent factors linked to pain occurrence in their study, where TEP and TAPP repairs were compared and pain scores at the 1st and 24th postoperative hours were both found to be lower in the TEP group (1.98 vs 2.79 and 1.09 vs 1.83 , respectively) and statistically significant $(P<0.0001$ vs $P=0.007){ }^{26}$

Ismail et al reported that in 480 patients who underwent TEP repair, $24 \mathrm{~h}$ after the surgery, the pain score was higher in the nonfixed group operated under GA and SA than in mesh-fixed group operated under SA, and it was statistically significant $(P=0.02) .{ }^{32}$ It was found that pain scores in the $1 \mathrm{st}$ and 4th postoperative hours were higher in the GA group than in the SA group (4.80 vs 0.16 and 2.32 vs 1.72 , respectively), and they were significantly different $(P<0.0001$ vs $P=0.002$; Figure 2). Although the pain scores during the 12th and 24th

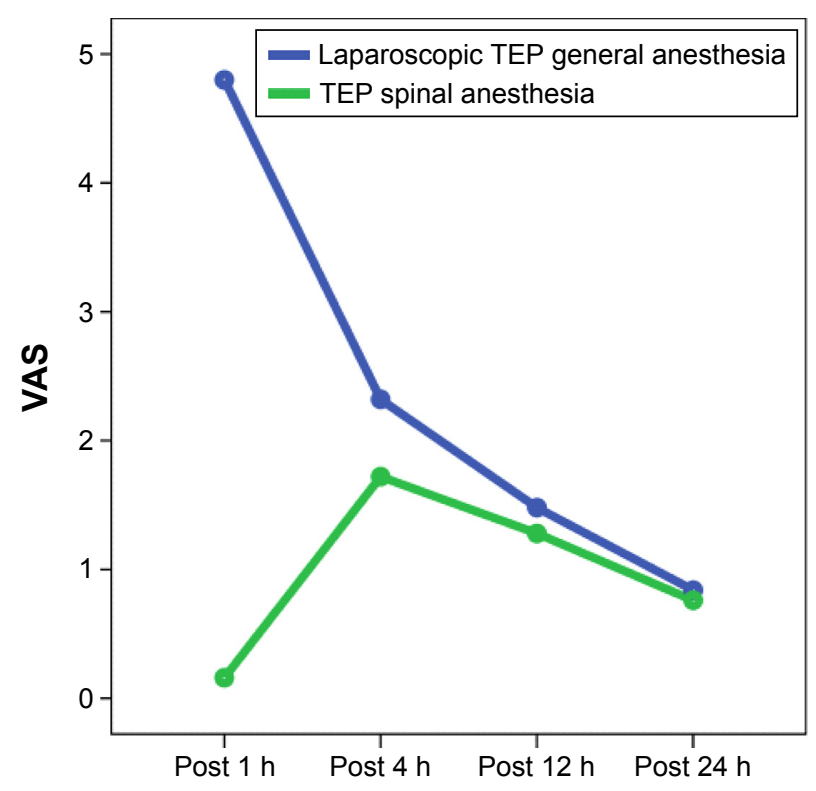

Figure 2 Postoperative pain graphics.

Abbreviations: TEP, total extraperitoneal; VAS, visual analog scale; $h$, hours. 
postoperative hours were a little bit higher in the GA group, there was no statistically significant difference between the groups ( $P=0.214$ vs $P=0.638)$.

Sinha et al reported conversion to GA in $3(0.63 \%)$ of 480 patients who underwent TEP under SA. ${ }^{15}$ Another study reported $3.8 \%$ of the TEP cases operated under GA were converted to TAPP repair. ${ }^{25}$ In the present study, conversion neither from TEP to TAPP nor from SA to GA occurred. Recurrence rates for TEP repair were reported to be between $1 \%$ and $2 \% .{ }^{40,41}$ In the present study, no recurrence was found during the 11-month follow-up period in either group.

As for patient satisfaction, it was found that Likert satisfaction survey scores in the group of TEP under SA were higher than those in the group of TEP under GA (4.44 vs 3.96) and that this was statistically significant $(P=0.020)$. From the survey, it was found that the main cause for this was high pain scores early in the postoperative period in the GA group, which required analgesic use. In contrast, the Karnofsky Performance Scale yielded no difference between the two groups $(P=0.687)$.

As a result, anesthesia-related adverse effects, such as spinal headache and urinary retention, are found in TEP repair under SA. In addition, if a peritoneal tear occurs peroperatively, it may cause mild or moderate shoulder pain. Nevertheless, SA seems to be more advantageous than GA in terms of hypotension, vomiting, and pain during the early postoperative period. Besides that, it also works as a good muscle relaxant. Patients seem to have increased satisfaction because they are conscious and can watch the procedure on a monitor during the surgery. It was found that better satisfaction was found in those who underwent surgery under the SA technique.

TEP repair under SA is a safe, effective, and applicable method. Less number of patients (in total 50 patients) was the disadvantage of the present study. However, though this study was the first to compare the GA and SA in TEP surgery, the results will be valuable and a leading one for surgeons in laparoscopic hernia repairs. However, large series of randomized studies are required to fully determine its advantages and disadvantages.

\section{Disclosure}

The authors report no conflicts of interest in this work.

\section{References}

1. Everhart JE, editor. Digestive Diseases in the United States: Epidemiology and Impact. U.S. Department of Health and Human Services, Public Health Service, National Institutes of Health, National Institute of Diabetes and Digestive and Kidney Diseases. Washington, DC: U.S. Government Printing Office; 1994. NIH publication no. 94-1447.
2. Mathavan VK, Arregui ME. Fixation versus no fixation in laparoscopic TEP and TAPP. The SAGES Manual of Hernia Repair. New York: Springer. 2013:203-212.

3. Lauscher JC, Yafaei K, Buhr HJ, Ritz JP. Laparoscopic and open inguinal hernia repair with alloplastic material: do the subjective and objective parameters differ in the long-term course? Surg Laparosc Endosc Percutan Tech. 2008;18:457-463.

4. Kuhry E, Veen RN, Langeveld HR, Steyerberg EW, Jeekel J, Bonjer HJ Open or endoscopic total extraperitoneal inguinal hernia repair? a systematic review. Surg Endosc. 2007;21:161-166.

5. Andersson B, Hallen M, Bergenfelz A, Westerdahl J. Laparoscopic extraperitoneal inguinal hernia repair versus open mesh repair: a prospective randomized controlled trial. Surgery. 2003;133:464-472.

6. Park A, Birch DW, Lovrics P. Laparoscopic and open incisional hernia repair: a comparison study. Surgery. 1998;124:816-822.

7. Belyansky I, Tsirline VB, Klima DA, Walters AL, Lincourt AE, Heniford TB. Prospective, comparative study of postoperative quality of life in TEP, TAPP, and modified Lichtenstein repairs. Ann Surg. 2011; 254:709-714.

8. Neumayer L, Giobbie-Hurder A, Jonasson O, et al. Open mesh versus laparoscopic mesh repair of inguinal hernias. N Eng J Med. 2004;350: 1819-1827.

9. McCormick K, Scott NW, Go PM, Ross S, Grant AM; EU Hernia Trialists Collaboration. Laparoscopic technique versus open technique for inguinal hernia repair. Cochrane Database Syst Rev. 2003;(1): CD001785.

10. Swanstrom L. Laparoscopic surgery: laparoscopic herniorrhaphy. Surg Clinics North Am. 1996;73:483-491.

11. Ferzli G, Sayad P, Vasisht B. The feasibility of laparoscopic extraperitoneal hernia repair under local anesthesia. Surg Endosc. 1999;13: 588-590.

12. Pendurthi TK, Demaria FJ, Kellum JM. Laparoscopic bilateral inguinal hernia repair under local anesthesia. Surg Endosc. 1995;9:197-199.

13. Molinelli BM, Tagliavia A, Bernstein D. Total extraperitoneal preperitoneal laparoscopic hernia repair using spinal anesthesia. JSLS. 2006; 10(3):341-344.

14. Lau H, Wong C, Chu K, Patil NG. Endoscopic totally extraperitoneal inguinal hernioplasty under spinal anesthesia. J Laparoendosc Adv Surg Tech A. 2005;15(2):121-124.

15. Sinha R, Gurwara AK, Gupta SC. Laparoscopic total extraperitoneal inguinal hernia repair under spinal anesthesia: a study of 480 patients. J Laparoendosc Adv Surg Tech A. 2008;18(5):673-677.

16. National Institute for Clinical Excellence. Guidance on the Use of Laparoscopic Surgery for Inguinal Hernia, Technological Appraisal Guidance No. 18. London: NICE; 2001.

17. Takata MC, Duh QY. Laparoscopic inguinal hernia repair. Surg Clin North Am. 2008;88:157-178.

18. Sung TY, Kim MS, Cho CK, et al. Clinical effects of intrathecal fentanyl on shoulder tip pain in laparoscopic total extraperitoneal inguinal hernia repair under spinal anaesthesia: a double-blind, prospective, randomized controlled trial. J Int Med Res. 2013;41(4):1160-1170.

19. Felix EL, Harbertson N, Vartanian S. Laparoscopic hernioplasty: significant complications. Surg Endosc. 1999;13:328-331.

20. Bringman $S$, Blomqvist $P$. Intestinal obstruction after inguinal and femoral hernia repair: a study of 33,275 operations during 1992-2000 in Sweden. Hernia. 2005;9:178-183.

21. Moreno-Egea A, Aguayo JL, Canteras M. Intraoperative and postoperative complications of totally extraperitoneal laparoscopic inguinal hernioplasty. Surg Laparosc Endosc Percutan Tech. 2000;10:30-33.

22. Lau H, Lee F, Patil N, Yuen WK. Laparoscopic totally extraperitoneal inguinal hernioplasty: an audit of the early postoperative results of 100 consecutive repairs. Ann Acad Med Singapore. 2000;29(5):640-643.

23. Misra MC, Kumar S, Kumar BV, Krishna A. Guidelines for laparoscopic (TAPP) and endoscopic (TEP) treatment of inguinal Hernia [International Endohernia Society (IEHS)]. Surg Endosc. 2011;25: 2773-2843.

24. Lau H, Lee F. Seroma following endoscopic extraperitoneal inguinal hernioplasty. Surg Endosc. 2003;17:1773-1777. 
25. Misra MC, Kumar S, Bansal VK. Total extraperitoneal (TEP) mesh repair of inguinal hernia in the developing world: comparison of low-cost indigenous balloon dissection versus direct telescopic dissection: a prospective randomized controlled study. Surg Endosc. 2008; 22:1947-1958.

26. Krishna A, Misra MC, Bansal VK, Kumar S, Rajeshwari S, Chabra A. Laparoscopic inguinal hernia repair: transabdominal preperitoneal (TAPP) versus totally extraperitoneal (TEP) approach: a prospective randomized controlled trial. Surg Endosc. 2012;26(3):639-649.

27. Haidenberg J, Kendrick ML, Meile T, Farley DR. Totally extraperitoneal (TEP) approach for inguinal hernia: the favorable learning curve for trainees. Curr Surg. 2003;60(1):65-68.

28. Kwon KH, Son BH, Han WK. Laparoscopic totally extraperitoneal repair without suprapubic port: comparison with conventional totally extraperitoneal repair. J Korean Surg Soc. 2011;80(5):319-326.

29. Goo TT, Lawenko M, Cheah WK, Tan C, Lomanto D. Endoscopic total extraperitoneal repair of recurrent inguinal hernia: a 5-year review. Hernia. 2010;14(5):477-480.

30. Garg P, Menon GR, Rajagopal M, Ismail M. Laparoscopic total extraperitoneal repair of recurrent inguinal hernias. Surg Endosc. 2010;24(2):450-454.

31. Choi YY, Han SW, Bae SH, Kim SY, Hur KY, Kang GH. Comparison of the outcomes between laparoscopic totally extraperitoneal repair and prolene hernia system for inguinal hernia; review of one surgeon's experience. J Korean Surg Soc. 2012;82(1):40-44.

32. Ismail M, Garg P. Laparoscopic inguinal total extraperitoneal hernia repair under spinal anesthesia without mesh fixation in 1,220 hernia repairs. Hernia. 2009;13(2):115-119.
33. Yousefshahi F, Dahmardeh AR, Khajavi M, Najafi A, Khashayar P, Barkhordari K. Effect of dexamethasone on the frequency of postdural puncture headache after spinal anesthesia for cesarean section: a doubleblind randomized clinical trial. Acta Neurol Belg. 2012;112:345-350.

34. Esmaoglu A, Akpinar H, Ugur F. Oral multidose caffeine-paracetamol combination is not effective for the prophylaxis of postdural puncture headache. J Clin Anesth. 2005;17:58-61.

35. Myles PS, Williams DL, Hendrata M, Anderson H, Weeks AM. Patient satisfaction after anaesthesia and surgery: results of a prospective survey of 10,811 patients. Br J Anaesth. 2000;84:6-10.

36. Junger A, Hartmann B, Benson M, et al. The use of an anesthesia information management system for prediction of antiemetic rescue treatment at the postanesthesia care unit. Anesth Analg. 2001;92:1203-1209.

37. Apfel CC, Läärä E, Koivuranta M, Greim CA, Roewer N. A simplified risk score for predicting postoperative nausea and vomiting: conclusions from cross-validations between two centers. Anesthesiology. 1999;91: 693-700.

38. Lau H, Patil NG, Yuen WK, Lee F. Management of peritoneal tear during endoscopic extraperitoneal inguinal hernioplasty. Surg Endosc. 2002;16:1474-1477.

39. Spivak H, Nudelman I, Fuco V, et al. Laparoscopic extraperitoneal inguinal hernia repair with spinal anesthesia and nitrous oxide insufflation. Surg Endosc. 1999;13:1026-1029.

40. Lau H, Patil NG, Yuen WK, Lee F. Prevalence and severity of chronic groin pain after endoscopic totally extraperitoneal inguinal hernioplasty. Surg Endosc. 2003;17:1620-1623.

41. Weiser HF, Klinge B. Endoscopic hernia repair - experiences and characteristic features. Viszeralchirurgie. 2000;35:316-320.
Therapeutics and Clinical Risk Management

\section{Publish your work in this journal}

Therapeutics and Clinical Risk Management is an international, peerreviewed journal of clinical therapeutics and risk management, focusing on concise rapid reporting of clinical studies in all therapeutic areas outcomes, safety, and programs for the effective, safe, and sustained use of medicines. This journal is indexed on PubMed Central, CAS,

\section{Dovepress}

EMBase, Scopus and the Elsevier Bibliographic databases. The manuscript management system is completely online and includes a very quick and fair peer-review system, which is all easy to use. Visit http://www.dovepress.com/testimonials.php to read real quotes from published authors. 